\title{
Design and development of a novel magnetic camphor nanospheres core/shell nanostructure
}

\author{
Ali Maleki ${ }^{1}\left[\right.$ Pedram Zand $^{1} \cdot$ Zahra Mohseni $^{1}$
}

Received: 4 February 2017 / Accepted: 6 March 2017/Published online: 11 March 2017

(C) The Author(s) 2017. This article is published with open access at Springerlink.com

\begin{abstract}
In this work, the first synthesis, characterization and catalytic performance of $\mathrm{Fe}_{3} \mathrm{O}_{4} /$ camphor core/shell nanospheres as a magnetic composite nanocatalyst were reported. The characterization was carried out by Fourier transform infrared spectroscopy, field-emission scanning electron microscopy, transmission electron microscopy, $\mathrm{X}$-ray diffraction, energy-dispersive X-ray spectroscopy, thermogravimetric analysis, vibrating sample magnetometer, $\mathrm{N}_{2}$ adsorption-desorption by Brunauer-Emmett-Teller and inductively coupled plasma analyses. The recoverable heterogeneous nanostructure catalyst was simply prepared and effectively employed in the one-pot multicomponent synthesis of $\beta$-amino carbonyl compounds in ethanol as a green solvent at room temperature. Further advantages of this new protocol are short reaction times, high yields, easy workup procedure, inexpensive and eco-friendly protocol and magnetically recoverability and several times reusability of the nanocatalyst without significant decrease in catalytic activity.
\end{abstract}

Keywords $\mathrm{Fe}_{3} \mathrm{O}_{4} /$ camphor core/shell $\cdot$ Nanostructure . Nanocatalyst $\cdot$ Multicomponent reaction $\cdot \beta$-Amino carbonyl $\cdot$ Mannich reaction

Ali Maleki

maleki@iust.ac.ir

1 Catalysts and Organic Synthesis Research Laboratory, Department of Chemistry, Iran University of Science and Technology, Tehran 16846-13114, Iran

\section{Introduction}

Due to significance of catalysis, this area is a highly important object among various green chemistry principals [1]. The catalytic reactions may reduce energy requirements and decrease separation steps because of their increased selectivity. Moreover, catalysis is of crucial importance for the chemical industry to make key products like biologically important heterocyclic compounds and various fine chemicals $[2,3]$. By utilizing catalysts, organic reactions can be more efficient and selective through decreasing of by-products and wastes [4]. The area of nanocatalysis which involves a substance or material with catalytic properties that possesses at least one nanoscale dimension in their structures is undergoing an explosive development. Nanocatalysis can help design catalysts with excellent activity, greater selectivity, and high stability [5-8]. Composite nanocatalysts, especially supported magnetic metal oxides nanoparticles (MNPs), have attracted considerable interest of researchers, because of their potential applications in chemical, biomedical and materials science. Due to intrinsic properties of $\mathrm{Fe}_{3} \mathrm{O}_{4}$ MNPs including high surface area, low toxicity and superparamagnetic behavior, they have received a great deal of attention in various academic and technological applications [9-14]. Recently, a number of such functionalized $\mathrm{Fe}_{3} \mathrm{O}_{4}$ nanoparticles, especially core/shell nanostructures have been employed in a range of organic transformations $[15,16]$. They are widely used in the synthesis of biologically active compounds, such as drug delivery systems, magnetic resonance imaging (MRI), biosensors, bioseparation and magneto-thermal therapy [17]. On the other hand, some comprehensive reports have been described in the literature as micromeritics such as nanospheres, nanorods, nanofibers, nanoreefs, nanoboxes [18]. One of the most famous atom-efficient multicomponent reactions is Mannich reaction which involves carbon-carbon 
bond formation between an enolizable ketone as a nucleophile and a Schiff base as an electrophile to provide $\beta$-amino carbonyl compounds [19]. Most of the previously described methods suffer from drawbacks, e.g., long reaction times, large amounts of catalysts, expensive reagents or catalysts, toxicity, harsh reaction conditions and low yields. As a result, design and introduction of green, biocompatible and inexpensive catalyst for the synthesis of $\beta$-amino carbonyl compounds is of prime importance.

Natural camphor is affordable and has also medicinal and catalyst properties. The cool and aromatic camphor can be used to alleviate skin itching and irritation. By applying camphor on the affected areas, the compound in camphor activates the nerve endings, and this produces a soothing sensation. It not only provides relief from itching and irritation but also reduces incidences of redness on the skin. Natural camphor includes other properties, such as soothes burns, cures acne, fungal and bacterial infections and promotes blood circulation [20]. Our research group after much research on natural camphor decided to use it for surface modification of $\mathrm{Fe}_{3} \mathrm{O}_{4}$ nanoparticles.

In continuation of our research on green nanocatalysts and organic synthesis [21-28], herein, we wish to report $\mathrm{Fe}_{3} \mathrm{O}_{4} /$ camphor nanospheres as a novel, efficient, ecofriendly, superparamagnetic and heterogeneous catalyst and investigation of its application in the synthesis of $\beta$ amino carbonyl compounds 4 via the condensation reaction of aniline $\mathbf{1}$, an aldehyde $\mathbf{2}$ and a ketone $\mathbf{3}$ (Scheme 1).

To the best of our knowledge, this is the first report of design, preparation, and characterization $\mathrm{Fe}_{3} \mathrm{O}_{4}$ /camphor core/shell nanospheres and its application as a heterogeneous catalyst in the synthesis of $\beta$-amino carbonyl compounds. We have used camphor as a naturally abundant biocompatible material by combining with $\mathrm{Fe}_{3} \mathrm{O}_{4}$ nanoparticles to yield $\mathrm{Fe}_{3} \mathrm{O}_{4} /$ camphor nanospheres as a recyclable, economical and inexpensive catalyst.

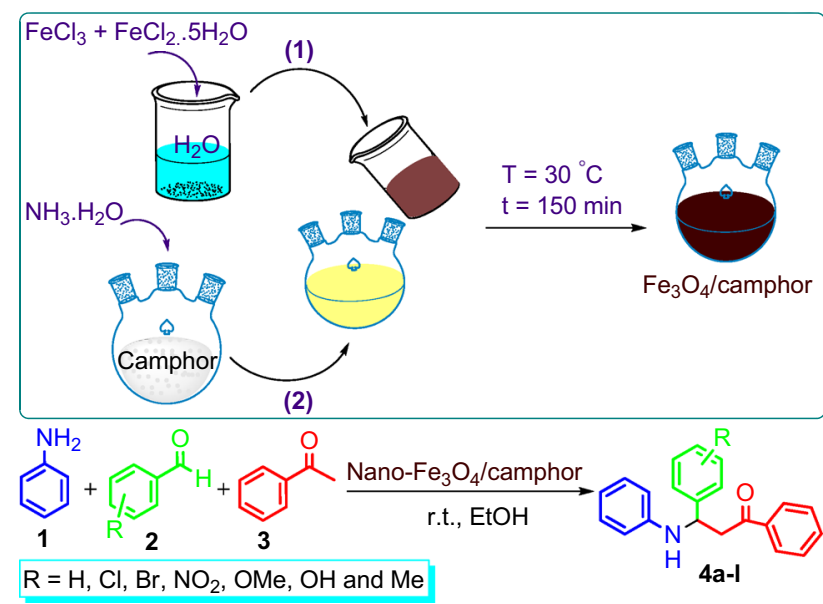

Scheme $1 \mathrm{Fe}_{3} \mathrm{O}_{4} /$ camphor-catalyzed synthesis of $\beta$-amino carbonyl products $\mathbf{4 a - 1}$

\section{Experimental}

\section{General}

All the solvents, chemicals and reagents were purchased from Merck, Sigma and Aldrich. Melting points were measured on an Electrothermal 9100 apparatus and are uncorrected. Fourier transform infrared spectroscopy (FTIR) spectra were recorded on a Shimadzu IR-470 spectrometer by the method of $\mathrm{KBr}$ pellet. ${ }^{1} \mathrm{H}$ and ${ }^{13} \mathrm{C}$ NMR spectra were recorded on a Bruker DRX-300 Avance spectrometer at 300.13 and $75 \mathrm{MHz}$, respectively. Fieldemission scanning electron micrograph (FE-SEM) images were taken with Sigma Zeiss microscope with attached camera. Transmission electron microscopy (TEM) was performed on a Philips CM10 operated at an $80 \mathrm{kV}$ electron beam accelerating voltage. Magnetic measurements of the solid samples were performed using a Lakeshore 7407 and Meghnatis Kavir Kashan Co., Iran vibrating sample magnetometer (VSMs). A Netzsch Thermoanalyzer STA 504 was used for the thermogravimetric analysis (TGA) with a heating rate of $10{ }^{\circ} \mathrm{C} / \mathrm{min}$ under air atmosphere. Elemental analysis of the nanocatalyst was carried out by energy-dispersive X-ray spectroscopy (EDX) spectra recorded on Numerix DXP-X10P. X-ray diffraction patterns were recorded with an $X^{\prime}$ Pert Pro $X$-ray diffractometer operating at $40 \mathrm{~mA}, 40 \mathrm{kV}$. The specific surface area was measured via BET $\mathrm{N}_{2}$ adsorption-desorption method using a Nansord92 instrument. Inductively coupled plasma (ICP) analyzed on a Shimadzu ICPS-7000.

\section{Preparation of $\mathrm{Fe}_{3} \mathrm{O}_{4} /$ camphor nanospheres}

$\mathrm{Fe}_{3} \mathrm{O}_{4} /$ camphor nanospheres employing coprecipitation in situ method has been prepared in accordance with the following conditions [26]. In a typical procedure, $2.4 \mathrm{~g}$ of $\mathrm{FeCl}_{3}$ and $3 \mathrm{~g}$ of $\mathrm{FeCl}_{2} \cdot 5 \mathrm{H}_{2} \mathrm{O}$ were dissolved in $100 \mathrm{~mL}$ of deionized water. Then, $2 \mathrm{~g}$ of camphor and $10 \mathrm{~mL}$ of $\mathrm{NH}_{3} \cdot \mathrm{H}_{2} \mathrm{O}$ were mixed at $30{ }^{\circ} \mathrm{C}$ in a three-necked flask. Then, mixture of $\mathrm{FeCl}_{3}$ and $\mathrm{FeCl}_{2} \cdot 5 \mathrm{H}_{2} \mathrm{O}$ was added in drops in ammonia containing camphor for $150 \mathrm{~min}$ at $30{ }^{\circ} \mathrm{C}$. The obtained $\mathrm{Fe}_{3} \mathrm{O}_{4}$ /camphor precipitate was washed repeatedly with deionized water until $\mathrm{pH}$ value decreased to 7 and then dried at $80{ }^{\circ} \mathrm{C}$ in an oven.

\section{General procedure for the synthesis of $\beta$-amino carbonyl compounds 4a-I}

A mixture of aromatic aldehyde $(2.0 \mathrm{mmol})$ and amine $(2.0 \mathrm{mmol})$ in absolute $\mathrm{EtOH}(4 \mathrm{~mL})$ was added to the $\mathrm{Fe}_{3} \mathrm{O}_{4} /$ camphor nanospheres $(0.015 \mathrm{~g})$. The mixture was stirred at room temperature for 10-15 min until the starting 
materials had almost disappeared (monitored by thin layer chromatograph, TLC). The ketone $(3.0 \mathrm{mmol})$ was then added, and the mixture was stirred for the appropriate time until the reaction was complete as monitored by TLC. The catalyst was separated easily by an external magnet and reused as such for the next experiments. The products were isolated pure just by recrystallization from hot $\mathrm{EtOH}$ and no more purification was needed.

\section{Spectral data of 3-(4-chlorophenyl)-1-phenyl-3-( $N$ - phenylamino)propan-1-oneediates $4 \mathrm{~d}$}

Yellow crystalline solid: $\mathrm{mp} 117{ }^{\circ} \mathrm{C}$. FT-IR $(\mathrm{KBr})\left(\mathrm{v}_{\max }\right.$, $\mathrm{cm}^{-1}$ ): 750, 825, 1510, 1602, 1668, 2850, 2918, 3055, 3392. ${ }^{1} \mathrm{H}$ NMR (300 MHz, DMSO- $d_{6}$ ) $(\delta, \mathrm{ppm}): 2.09-2.36$ $\left(\mathrm{m}, 1 \mathrm{H}, \mathrm{CH}_{2}\right), 3.60-3.69\left(\mathrm{~m}, 1 \mathrm{H}, \mathrm{CH}_{2}\right), 5.01(\mathrm{~m}, 1 \mathrm{H}, \mathrm{CH})$, $6.25(\mathrm{~m}, 1 \mathrm{H}, \mathrm{NH}), 6.65$ (d, 2H, H-Ar), 6.77 (t, 1H, H-Ar), 7.13 (t, 2H, H-Ar), 7.26-7.62 (m, 7H, H-Ar), 7.87-7.91 (m, $2 \mathrm{H}, \mathrm{H}-\mathrm{Ar}) .{ }^{13} \mathrm{C}$ NMR $\left(75 \mathrm{MHz}, \mathrm{DMSO}-d_{6}\right)(\delta, \mathrm{ppm}): 46.0$,

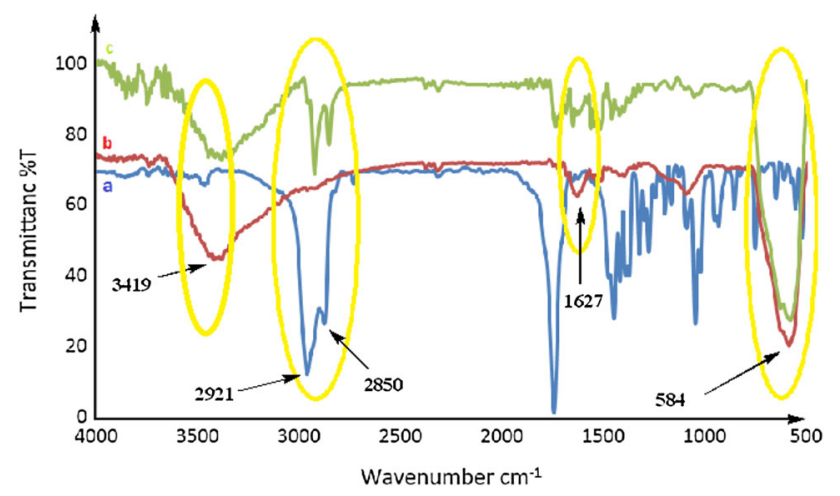

Fig. 1 The comparative FT-IR spectra of: $a$ camphor, $b \mathrm{Fe}_{3} \mathrm{O}_{4}$ and $c \mathrm{Fe}_{3} \mathrm{O}_{4} /$ camphor
54.3, 114.0, 118.1, 127.8, 128.1 128.7, 128.9, 129.1, 133.0, 133.4, 136.7, 141.5, 146.7, 197.8 .

\section{Results and discussion}

\section{Characterization of the prepared $\mathrm{Fe}_{3} \mathrm{O}_{4}$ /camphor nanospheres}

$\mathrm{Fe}_{3} \mathrm{O}_{4} /$ camphor nanospheres were prepared by in situ coprecipitation method. As can be seen in Fig. 1, the FT-IR spectrum of the $\mathrm{Fe}_{3} \mathrm{O}_{4}$ /camphor magnetic nanocatalyst can verify the preparation of the expected product. The bending vibration band at $584 \mathrm{~cm}^{-1}$ and stretching vibration band at $1627 \mathrm{~cm}^{-1}$ are induced by structure $\mathrm{Fe}-\mathrm{O}$ vibration. A broad O-H stretch around $3419 \mathrm{~cm}^{-1}$ was observed in the $\mathrm{Fe}_{3} \mathrm{O}_{4}$. The $\mathrm{C}-\mathrm{H}$ stretching vibrations observed at 2850 and $2921 \mathrm{~cm}^{-1}$ indicate that the camphor was successfully formed with $\mathrm{Fe}_{3} \mathrm{O}_{4}$ nanospheres.

To clarify the morphology of the nanocatalyst, FE-SEM images of $\mathrm{Fe}_{3} \mathrm{O}_{4} /$ camphor are presented in Fig. 2. As it obvious, obtained catalyst has a uniform and spherical morphology. In addition, the claim of nanosized catalyst was proved by FE-SEM images. The average particle size distribution was about $50 \mathrm{~nm}$.

Figure 3 shows the results of the EDX spectrum of the magnetite $\mathrm{Fe}_{3} \mathrm{O}_{4} /$ camphor nanospheres. The presence of iron, carbon and oxygen elements clearly confirmed that $\mathrm{Fe}_{3} \mathrm{O}_{4} /$ camphor nanocatalyst was synthesized.

Figure 4 shows the XRD measurements were performed with the dried powder samples of bare and mixture of the $\mathrm{Fe}_{3} \mathrm{O}_{4}$ NPs with camphor to identify the crystal phases present in the samples. The XRD pattern of a representative $\mathrm{Fe}_{3} \mathrm{O}_{4} /$ camphor (curve a) along with bare $\mathrm{Fe}_{3} \mathrm{O}_{4}$ NPs
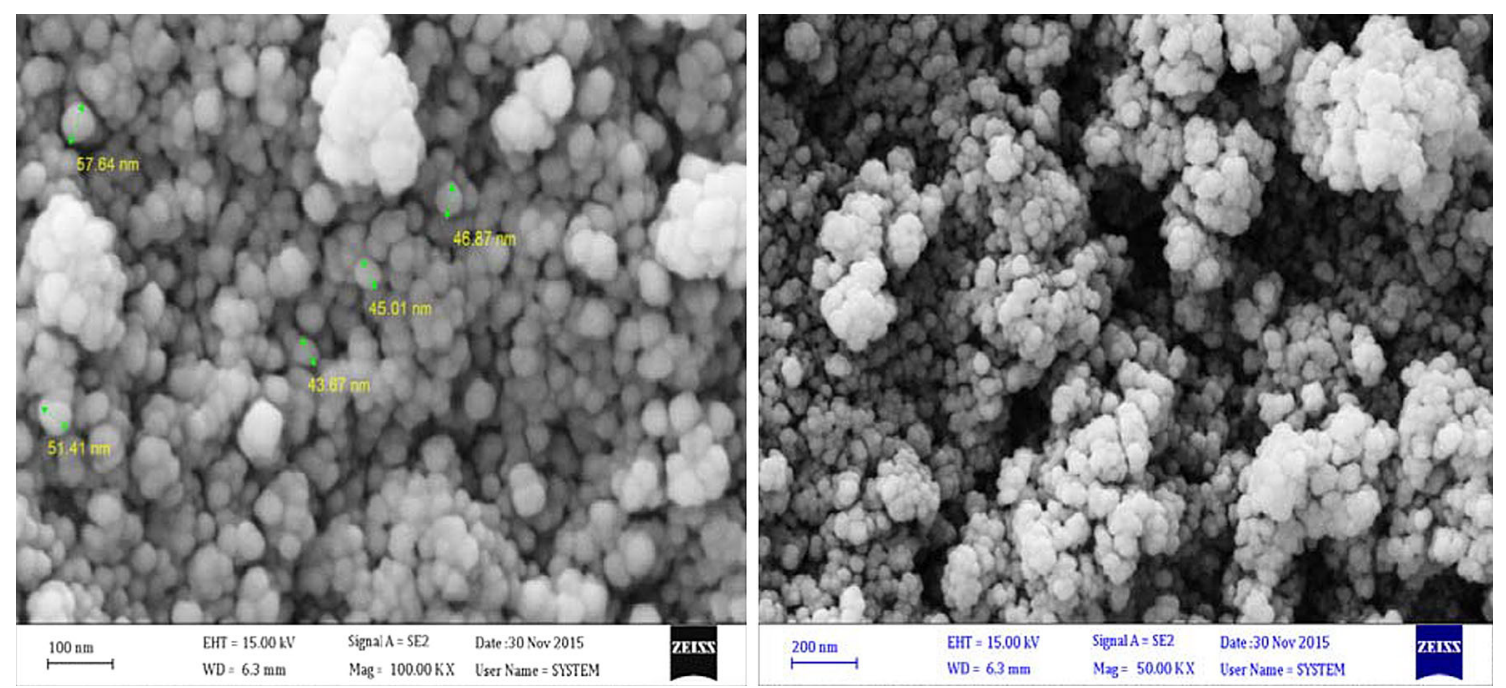

Fig. 2 FE-SEM images of $\mathrm{Fe}_{3} \mathrm{O}_{4} /$ camphor nanocatalyst 


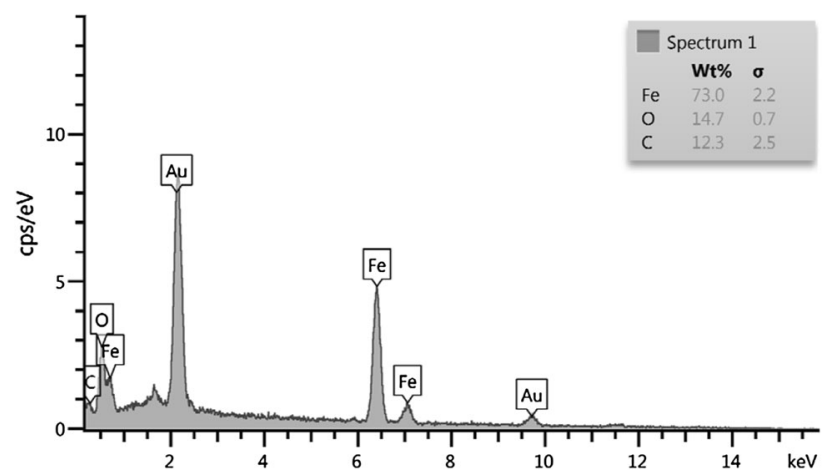

Fig. 3 EDX pattern of $\mathrm{Fe}_{3} \mathrm{O}_{4}$ /camphor nanocatalyst

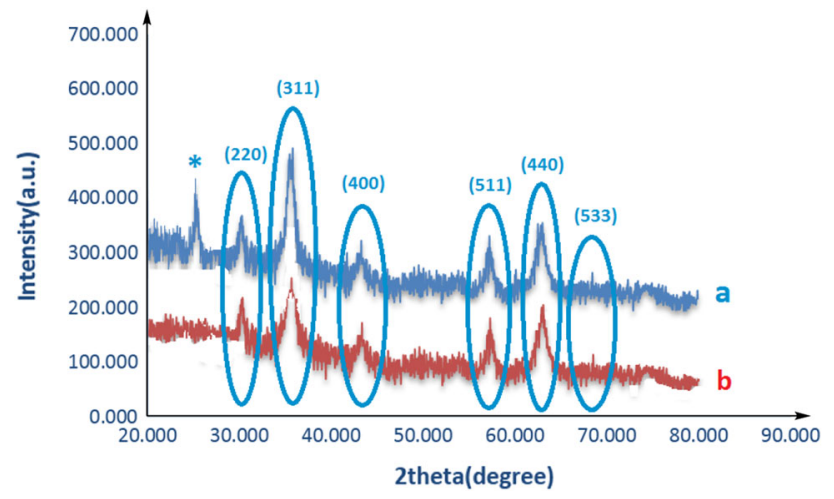

Fig. 4 XRD pattern of $\mathrm{Fe}_{3} \mathrm{O}_{4}$ /camphor $(a)$ and $\mathrm{Fe}_{3} \mathrm{O}_{4}(b)$. The symbol asterisk represents the camphor peak

(curve b) is shown. The pattern of the $\mathrm{Fe}_{3} \mathrm{O}_{4} /$ camphor showed all the major peaks corresponding to $\mathrm{Fe}_{3} \mathrm{O}_{4}$. The peaks at $2 \theta=30.23,35.63,43.34,57.25,62.84$ and 74.38 can be assigned to the (2 20$)$, (3 11 1), (4 00$)$, (5 11 1), (4 4 0 ), and ( $\left.\begin{array}{lll}5 & 3 & 3\end{array}\right)$ planes, respectively. The $\mathrm{Fe}_{3} \mathrm{O}_{4}$ NPs was also clearly confirmed by corresponding reference card (JCPDS\#19-0629). Additionally, one peak around $2 \theta=23^{\circ}$ along with small peaks due to the camphor are observed in the case of the $\mathrm{Fe}_{3} \mathrm{O}_{4} /$ camphor. This result confirmed that the mixture of $\mathrm{Fe}_{3} \mathrm{O}_{4} \mathrm{NPs}$ with camphor was formed.

The magnetic properties of the bare $\mathrm{Fe}_{3} \mathrm{O}_{4}$ and $\mathrm{Fe}_{3} \mathrm{O}_{4} /$ camphor were measured by VSM at room temperature. In Fig. 5, the hysteresis loops that are characteristic of superparamagnetic behavior can be clearly observed for all the nanoparticles. Superparamagnetism is the responsiveness to an applied magnetic field without retaining any magnetism after removal of the applied magnetic field. From the saturation magnetization value (Ms) of bare MNPs was found to be 68 emu g $\mathrm{g}^{-1}$. For $\mathrm{Fe}_{3} \mathrm{O}_{4} /$ camphor the magnetization obtained at the same field was $49 \mathrm{emu}$ $\mathrm{g}^{-1}$, lower than that of bare $\mathrm{Fe}_{3} \mathrm{O}_{4}$. This is mainly attributed to the existence of camphor mixed with the nanoparticles.

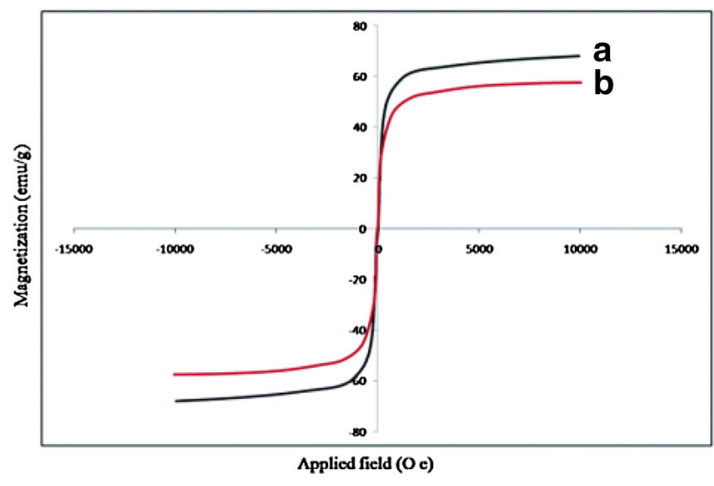

Fig. 5 VSM magnetization curves of the $a \mathrm{Fe}_{3} \mathrm{O}_{4}$ and $b \mathrm{Fe}_{3} \mathrm{O}_{4} /$ camphor

TEM was used to observe the morphology of $\mathrm{Fe}_{3} \mathrm{O}_{4} /$ camphor core/shell. Two different magnifications (a) and (b) TEM images of $\mathrm{Fe}_{3} \mathrm{O}_{4}$ /camphor and one TEM image of bare $\mathrm{Fe}_{3} \mathrm{O}_{4}$ synthesized without the camphor (c) are shown in Fig. 6. The images (a) and (b) show that the nanostructure has nanospheres morphology. The natural camphor was suitably mixed in $\mathrm{Fe}_{3} \mathrm{O}_{4}$ nanoparticles. Therefore, natural camphor could reduce the aggregation of $\mathrm{Fe}_{3} \mathrm{O}_{4}$ nanoparticles and the particles dispersion was improved.

The thermal stability and composition ratio of camphor in the obtained $\mathrm{Fe}_{3} \mathrm{O}_{4}$ /camphor nanospheres was measured through the TGA under air atmosphere with heating rate of $10^{\circ} \mathrm{C} / \mathrm{min}$ within temperature range of $0-800{ }^{\circ} \mathrm{C}$. Figure 7 illustrates the TGA curve, depicting the variations of the residual masses of the samples with temperature. The organic material and magnetite of the sample were completely burned to generate gas products and converted into iron oxides at the elevated temperature, respectively. The composition ratio of camphor in the obtained $\mathrm{Fe}_{3} \mathrm{O}_{4} / \mathrm{cam}$ phor nanospheres was estimated from the residual mass percentage. The magnetic content was about $86 \%$ and weight ratio of iron to camphor was 1:0.08. As shown in Fig. 7, the first weight loss stage (below $100{ }^{\circ} \mathrm{C}$ ) can be ascribed to the evaporation of water molecules in the composition. The next weight loss stage was started from about 400 to complete at $600{ }^{\circ} \mathrm{C}$ that was because of the decomposition of natural camphor. No further obvious decomposition exhibits a high thermal stability in comparison with similar structures.

Furthermore, inductively coupled plasma (ICP) analysis of the catalysts was provided. For this purpose, the four solutions with concentrations of 20,15, 10 and $5 \mathrm{ppm}$ of iron salts as standards were prepared. Then, a solution containing the nanocatalyst was prepared. The analysis revealed that the metal contents of the catalyst was close $( \pm 0.4 \%)$ to the target metal content of $75 \mathrm{wt} \% \mathrm{Fe}$. ICP 
Fig. 6 TEM images of $\mathrm{Fe}_{3} \mathrm{O}_{4} /$ camphor core/shell nanospheres with different magnifications: a $10 \mathrm{~nm}$ and b $25 \mathrm{~nm}$ and c TEM image of bare $\mathrm{Fe}_{3} \mathrm{O}_{4}$ nanoparticles
Fig. 7 TGA of $\mathrm{Fe}_{3} \mathrm{O}_{4} /$ camphor nanospheres
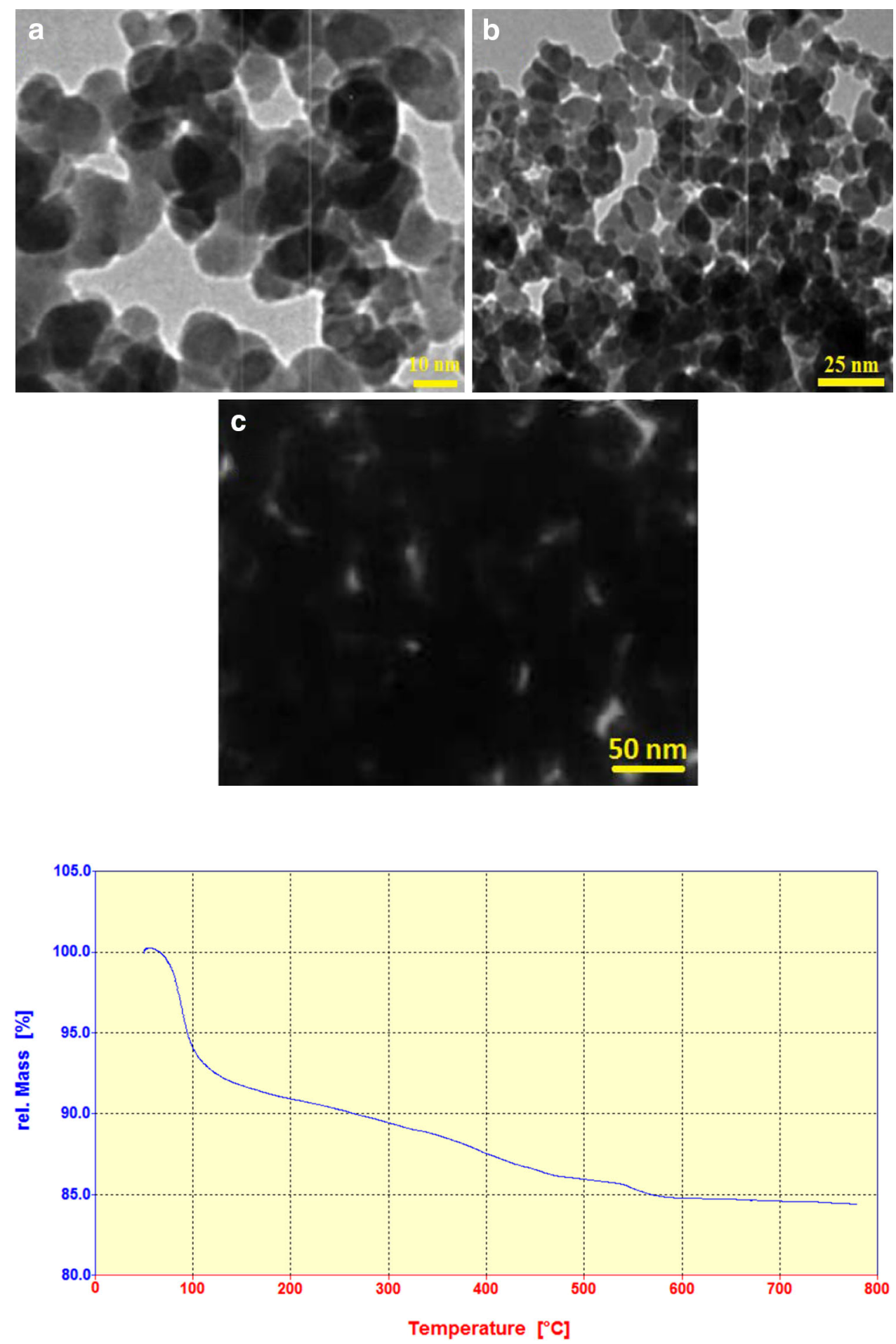

results are almost matched with the results obtained from EDX pattern analysis (73 wt $\% \mathrm{Fe})$.

The specific surface area of bare $\mathrm{Fe}_{3} \mathrm{O}_{4}$ nanoparticles and $\mathrm{Fe}_{3} \mathrm{O}_{4}$ /camphor were measured using BrunauerEmmett-Teller (BET) analysis with $\mathrm{N}_{2}$ adsorption-desorption. BET surface areas of bare $\mathrm{Fe}_{3} \mathrm{O}_{4}$ nanoparticles and
$\mathrm{Fe}_{3} \mathrm{O}_{4} /$ camphor were 95.25 and $53.04 \mathrm{~m}^{2} \mathrm{~g}^{-1}$ Respectively. Reduced specific surface area of $\mathrm{Fe}_{3} \mathrm{O}_{4} /$ camphor nanospheres compared with bare $\mathrm{Fe}_{3} \mathrm{O}_{4}$ nanoparticles can confirm that the mixture of camphor with $\mathrm{Fe}_{3} \mathrm{O}_{4}$ nanoparticles was made. 
Table 1 Optimization of the model reaction conditions
Table 2 Comparison of some catalyst effects with present nanocatalyst on the model reaction

\begin{tabular}{lllll}
\hline Entry & $\mathrm{Fe}_{3} \mathrm{O}_{4} /$ camphor nanospheres $(\mathrm{g})$ & Solvent & Time $(\mathrm{min})$ & Yield (\%) \\
\hline 1 & 0.005 & $\mathrm{EtOH}$ & 150 & 68 \\
2 & 0.015 & $\mathrm{EtOH}$ & 35 & 93 \\
3 & 0.020 & $\mathrm{EtOH}$ & 120 & 72 \\
4 & 0.025 & $\mathrm{EtOH}$ & 80 & 75 \\
5 & 0.015 & $\mathrm{MeOH}$ & 100 & 50 \\
6 & 0.015 & $\mathrm{H}_{2} \mathrm{O}$ & 80 & 55 \\
7 & 0.015 & $\mathrm{MeCN}$ & 110 & 45 \\
8 & 0.015 & $\mathrm{DMF}$ & 110 & 53 \\
9 & 0.015 & $n$-Hexane & 120 & 32 \\
10 & 0.015 & Ether & 120 & 35 \\
11 & 0.015 & Solvent-free & 100 & 20 \\
\hline
\end{tabular}

\begin{tabular}{llllll}
\hline Entry & Catalyst & Temperature $\left({ }^{\circ} \mathrm{C}\right)$ & Time & Yield $(\%)$ & Ref. \\
\hline 1 & Nano- $\mathrm{Fe}_{3} \mathrm{O}_{4} /$ camphor & r.t. & $35 \mathrm{~min}$ & 93 & This work \\
2 & $\mathrm{Nano}_{-} \mathrm{Fe}_{3} \mathrm{O}_{4}$ & r.t. & $45 \mathrm{~min}$ & 86 & This work \\
3 & $\mathrm{Camphor}$ & r.t. & $1 \mathrm{~h}$ & 75 & This work \\
4 & - & r.t. & $48 \mathrm{~h}$ & 15 & This work \\
5 & $\mathrm{BiCl}_{3}$ & r.t. & $4 \mathrm{~h}$ & 69 & {$[29]$} \\
6 & $\mathrm{HClO}_{4}-\mathrm{SiO}_{2}$ & r.t & $5 \mathrm{~h}$ & 68 & {$[30]$} \\
7 & $\mathrm{CaCl}_{2}$ & 80 & $2 \mathrm{~h}$ & 46 & {$[31]$} \\
8 & $\mathrm{Sulfated} \mathrm{MCM}-41^{2}$ & Reflux & $7 \mathrm{~h}$ & 83 & {$[32]$} \\
9 & ZnO-nanoparticles & 60 & $10 \mathrm{~h}$ & 85 & {$[19]$} \\
\hline
\end{tabular}

Table $3 \quad \mathrm{Fe}_{3} \mathrm{O}_{4} /$ camphor nanosphere-catalyzed synthesis of $\beta$-amino carbonyl compounds $\mathbf{4 a - 1}$

\begin{tabular}{|c|c|c|c|c|c|c|c|c|}
\hline \multirow[t]{2}{*}{ Entry } & \multirow[t]{2}{*}{$\mathrm{R}$} & \multirow[t]{2}{*}{ Product } & \multirow[t]{2}{*}{ Time (min) } & \multirow[t]{2}{*}{ TON } & \multirow[t]{2}{*}{ TOF $\left(h^{-1}\right)$} & \multirow[t]{2}{*}{ Yield $^{\mathrm{a}}(\%)$} & \multicolumn{2}{|c|}{$\mathrm{Mp}\left({ }^{\circ} \mathrm{C}\right)$} \\
\hline & & & & & & & Found & Reported \\
\hline 1 & 4-OMe & $4 a$ & 60 & 19.2 & 0.32 & 75 & 148 & $147-149$ [33] \\
\hline 2 & $4-\mathrm{Br}$ & $4 b$ & 35 & 23.07 & 0.659 & 90 & 128 & $127-129$ [34] \\
\hline 3 & 4-Me & $4 c$ & 60 & 17.94 & 0.299 & 70 & 131 & $130-132$ [35] \\
\hline 4 & $4-\mathrm{Cl}$ & $4 d$ & 35 & 23.84 & 0.681 & 93 & 117 & $116-119$ [36] \\
\hline 5 & $\mathrm{H}$ & $4 e$ & 60 & 20.51 & 0.341 & 80 & 170 & $169-170$ [33] \\
\hline 6 & $3-\mathrm{OH}$ & $4 f$ & 60 & 19.23 & 0.320 & 75 & 126 & $125-127[37]$ \\
\hline 7 & $3-\mathrm{NO}_{2}$ & $4 g$ & 40 & 21.79 & 0.544 & 85 & 141 & $140-142$ [38] \\
\hline 8 & $3-\mathrm{Br}$ & $4 h$ & 40 & 23.07 & 0.576 & 90 & 95 & $95-96$ [39] \\
\hline 9 & 3-OMe & $4 \mathbf{i}$ & 60 & 17.94 & 0.299 & 70 & 107 & $106-107$ [40] \\
\hline 10 & $2-\mathrm{NO}_{2}$ & $4 j$ & 50 & 20.51 & 0.410 & 80 & 160 & $158-162[31]$ \\
\hline 11 & $2-\mathrm{Cl}$ & $4 k$ & 50 & 21.79 & 0.435 & 85 & 52 & $52-53[40]$ \\
\hline 12 & 2-OMe & 41 & 60 & 16.66 & 0.277 & 65 & 122 & $122-124[41]$ \\
\hline
\end{tabular}

${ }^{a}$ Isolated yield

\section{Catalytic application of $\mathrm{Fe}_{3} \mathrm{O}_{4} /$ camphor in the synthesis of $\beta$-amino carbonyl compounds}

Initially, to optimize the reaction conditions for the synthesis of $\beta$-amino carbonyl compounds, various parameters on the reaction of aniline $(2 \mathrm{mmol})$, 4-chlorobenzaldehyde
( $2 \mathrm{mmol})$ and acetophenone $(3 \mathrm{mmol})$ as a pilot test were studied. First, the effect of catalyst amount on the reaction yield was studied. It was found that using $0.015 \mathrm{~g}$ of the $\mathrm{Fe}_{3} \mathrm{O}_{4} /$ camphor nanocatalyst is sufficient to complete the reaction and gives $\mathbf{4 d}$ after $35 \mathrm{~min}$ in $93 \%$ yield in $4 \mathrm{~mL}$ of $\mathrm{EtOH}$ as a green solvent at room temperature. 
Scheme 2 The proposed mechanism for the formation of $\beta$-amino carbonyl compounds 4a-l

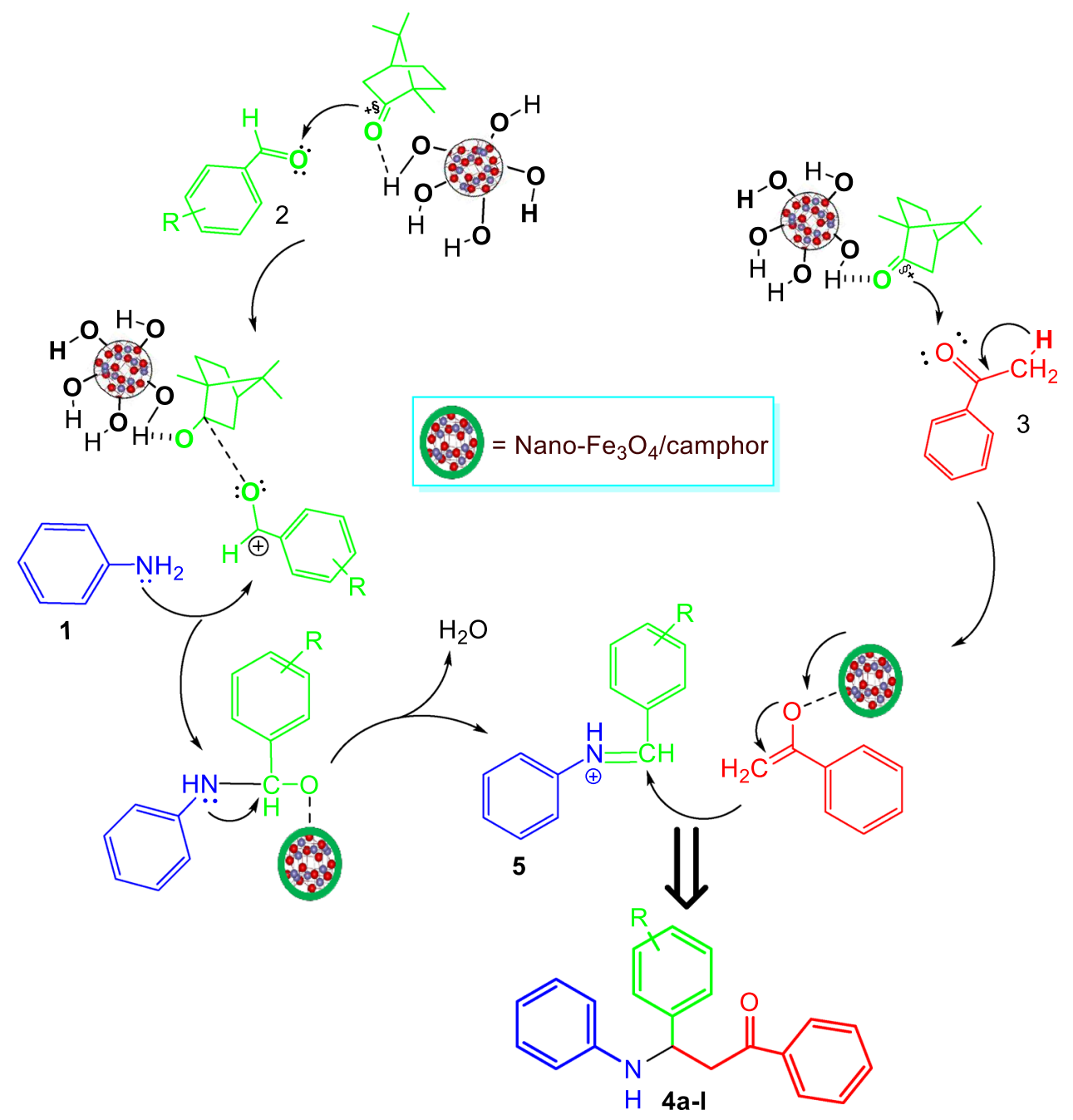

To compare the efficiency of ethanol, several solvents with different polarities were tested using the model reaction in the presence of $\mathrm{Fe}_{3} \mathrm{O}_{4}$ /camphor (Table 1). As it is obvious from the results, it was found that $\mathrm{EtOH}$ was the superior solvent for this study than $\mathrm{MeOH}, \mathrm{H}_{2} \mathrm{O}, \mathrm{MeCN}$, $\mathrm{DMF}$ and also under solvent-free conditions in the presence of $0.015 \mathrm{~g}$ of $\mathrm{Fe}_{3} \mathrm{O}_{4} /$ camphor catalyst at room temperature.

Finally, a comparison was made between the present work and others which were reported earlier for the synthesis of 4d. The results summarized in Table 2 clearly demonstrate the superiority of the present work over all the earlier reported ones in energy consumption, high-yield products and catalyst reusability.

The scope and limitations of the application of $\mathrm{Fe}_{3} \mathrm{O}_{4} /$ camphor in the synthesis of $\beta$-amino carbonyl compounds were investigated under optimized conditions. The summarized results in Table 3 show that all products, including electron-withdrawing-, electron-releasing- and halogensubstituted starting materials, were obtained in good-toexcellent yields after appropriate reaction times. The corresponding reaction times, yields, turnover number (TON) and turnover frequency (TOF) values, and also found and literature melting points of the products are listed in Table 3.

The suggested possible mechanism for the formation of $\beta$-amino carbonyl compounds 4a-l is shown in Scheme 2. At first, the carbonyl group of aldehyde 2 was activated by $\mathrm{Fe}_{3} \mathrm{O}_{4} /$ camphor nanospheres and become electrophilic group. Then, an amine $\mathbf{1}$ attacks the activated aldehyde $\mathbf{2}$ to form iminium $\mathbf{5}$. In addition, the enol form of ketone $\mathbf{3}$ was formed via tautomerisation in the presence of the nanocatalyst. Finally, the enol was added to $\mathbf{5}$ to yield the desired product 4 [42].

\section{Catalyst recyclability examination for $\mathrm{Fe}_{3} \mathrm{O}_{4}$ /camphor}

To study the catalyst reusability, the model reaction was carried out using $0.015 \mathrm{~g}$ of $\mathrm{Fe}_{3} \mathrm{O}_{4} /$ camphor. After completion of the reaction, nanospheres were separated using 


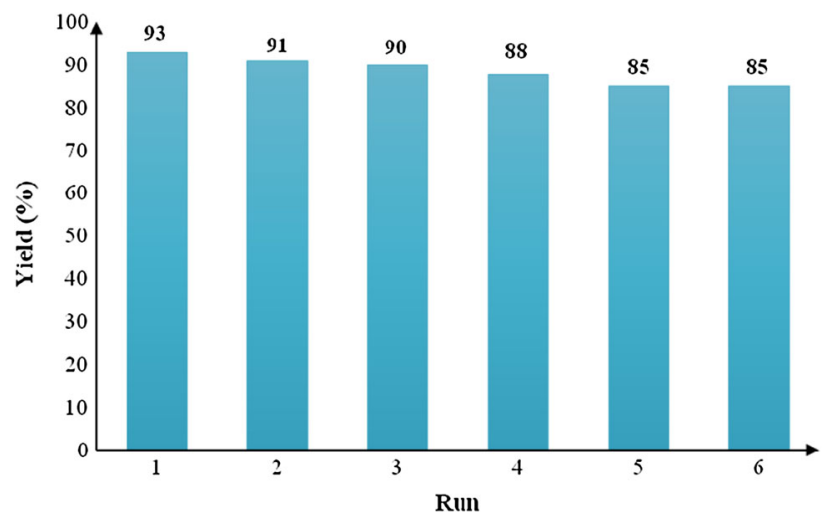

Fig. 8 Recycling of $\mathrm{Fe}_{3} \mathrm{O}_{4}$ /camphor nanocatalyst for the synthesis of 4d

an external magnet and washed with ethanol and water, dried and reused in another set of reaction. It was observed that the catalyst can be reused for six times without any significant reduction in product yield (Fig. 8). In addition, no extra care should be taken to store or handle the catalyst in recovery process; because, it does not have any air or moisture-sensitive nature.

\section{Conclusions}

In summary, eco-friendly, green and cost-effective $\mathrm{Fe}_{3} \mathrm{O}_{4} /$ camphor core/shell nanospheres as a reusable superparamagnetic nanocatalyst was described through a facile preparation process. Then, its morphology, structure and properties were characterized by FT-IR, TEM, TGA, EDX, FE-SEM, VSM, XRD, BET and ICP measurements. Then, its catalytic performance was studied in the synthesis of $\beta$-amino carbonyl compounds as Mannich products in high-to-excellent yields at room temperature. The nanocatalyst was easily recovered using an external magnet and efficiently reused several times without significant loss of activity. Furthermore, to the best of our literature survey, the present work is the first report on design, preparation and catalytic investigation of magnetized camphor.

Acknowledgements The authors gratefully acknowledge the partial support from the Research Council of the Iran University of Science and Technology.

Open Access This article is distributed under the terms of the Creative Commons Attribution 4.0 International License (http://crea tivecommons.org/licenses/by/4.0/), which permits unrestricted use, distribution, and reproduction in any medium, provided you give appropriate credit to the original author(s) and the source, provide a link to the Creative Commons license, and indicate if changes were made.

\section{References}

1. Anastas, P.T., Kirchhoff, M.M., Williamson, T.C.: Catalysis as a foundational pillar of green chemistry. Appl. Catal. A 221, 3-13 (2001)

2. Anastas, P.T., Kirchhoff, M.M.: Origins, current status, and future challenges of green chemistry. Acc. Chem. Res. 35, 686-694 (2002)

3. Vekariya, R.H., Patel, K.D., Patel, H.D.: Melamine trisulfonic acid (MTSA): an efficient and recyclable heterogeneous catalyst in green organic synthesis. RSC Adv. 5, 90819-90837 (2015)

4. Zeynizadeh, B., Karimkoshteh, M.: Magnetic $\mathrm{Fe}_{3} \mathrm{O}_{4}$ nanoparticles as recovery catalyst for preparation of oximes under solventfree condition. J. Nanostruct. Chem. 3, 57-63 (2013)

5. Polshettiwar, V., Luque, R., Fihri, A., Zhu, H., Bouhrara, M., Basset, J.M.: Magnetically recoverable nanocatalysts. Chem. Rev. 111, 3036-3075 (2011)

6. Shylesh, S., Schünemann, V., Thiel, W.R.: Magnetically separable nanocatalysts: bridges between homogeneous and heterogeneous catalysis. Angew. Chem. Int. Ed. 49, 3428-3459 (2010)

7. Lu, A., Salabas, E., Schüth, F.: Magnetic nanoparticles: synthesis, protection, functionalization, and application. Angew. Chem. Int. Ed. 46, 1222-1244 (2007)

8. Maleki, A., Kamalzare, M., Aghaei, M.: Efficient one-pot fourcomponent synthesis of 1,4-dihydropyridines promoted by magnetite/chitosan as a magnetically recyclable heterogeneous nanocatalyst. J. Nanostruct. Chem. 5, 95-105 (2015)

9. Montazeri, H., Amani, A., Shahverdi, H.R., Haratifar, E., Shahverdi, A.R.: Separation of the defect-free $\mathrm{Fe}_{3} \mathrm{O}_{4}-\mathrm{Au}$ core/shell fraction from magnetite-gold composite nanoparticles by an acid wash treatment. J. Nanostruct. Chem. 3, 25-31 (2013)

10. Khoee, S., Kavand, A.: A new procedure for preparation of polyethylene glycol-grafted magnetic iron oxide nanoparticles. J. Nanostruct. Chem. 3, 111 (2014)

11. Maleki, A., Rahimi, R., Maleki, S.: Preparation and characterization of magnetic chlorochromate hybrid nanomaterials with triphenylphosphine surface-modified iron oxide nanoparticles. J. Nanostruct. Chem. 4, 153-160 (2014)

12. Li, X., Cao, W.C., Liu, Y.G.: The property variation of magnetic mesoporous carbon modified by aminated hollow magnetic nanospheres: synthesis, characteristic and sorption. ACS Sustain. Chem. Eng. 5, 179-188 (2017)

13. Li, X., Wang, S.F.: Adsorption of $\mathrm{Cu}(\mathrm{II}), \mathrm{Pb}$ (II) and $\mathrm{Cd}(\mathrm{II})$ ions from acidic aqueous solutions by diethylenetriaminepentaacetic acid modified magnetic graphene oxide. J. Chem. Eng. Data 62, 407-416 (2017)

14. Zhu, Y., Xue, J., Xu, T., He, G., Chen, H.: Enhanced photocatalytic activity of magnetic core-shell $\mathrm{Fe}_{3} \mathrm{O}_{4} @ \mathrm{Bi}_{2} \mathrm{O}_{3}-\mathrm{RGO}$ heterojunctions for quinolone antibiotics degradation under visible light. J. Mater. Sci. 28, 1-10 (2017)

15. Petranovska, A.L., Abramov, N.V., Turanska, S.P., Gorbyk, P.P., Kaminskiy, A.N., Kusyak, V.V.: Adsorption of cis-dichlorodiamineplatinum by nanostructures based on single-domain magnetite. J. Nanostruct. Chem. 5, 257-258 (2015)

16. Abramov, N.V., Turanska, S.P., Kusyak, A.P., Petranovska, A.L., Gorbyk, P.P.: Synthesis and properties of magnetite/hydroxyapatite/doxorubicin nanocomposites and magnetic liquids based on them. J. Nanostruct. Chem. 6, 223-233 (2016)

17. Zhu, Y., Fang, Y., Kaskel, S.: Folate-conjugated $\mathrm{Fe}_{3} \mathrm{O}_{4} @ \mathrm{SiO}_{2}$ hollow mesoporous spheres for targeted anticancer drug delivery. J. Phys. Chem. C 114, 16382-16388 (2010)

18. Agam, M., Guo, Q.: Electron beam modification of polymer nanospheres. J. Nanosci. Nanotechnol. 7, 3615-3619 (2007) 
19. Kundu, K., Nayak, S.K.: ( \pm )-Camphor-10-sulfonic acid catalyzed direct one-pot three-component Mannich type reaction of alkyl (hetero) aryl ketones under solvent-free conditions: application to the synthesis of aminochromans. RSC Adv. 2, 480-486 (2011)

20. Cardoso, M.S., Correia, I., Galvao, A.M., Marques, F., Carvalho, M.F.: Synthesis of $\mathrm{Ag}(\mathrm{I})$ camphor sulphonylimine complexes and assessment of their cytotoxic properties against cisplatin-resistant A2780cisR and A2780 cell lines. J. Inorg. Biochem. 166, 55-63 (2017)

21. Maleki, A., Paydar, R.: Graphene oxide-chitosan bionanocomposite: a highly efficient nanocatalyst for the one-pot threecomponent synthesis of trisubstituted imidazoles under solventfree conditions. RSC Adv. 5, 33177-33184 (2015)

22. Maleki, A., Aghaei, M., Ghamari, N.: Efficient synthesis of 2, 3-dihydroquinazolin-4(1H)-ones in the presence of ferrite/chitosan as a green and reusable nanocatalyst. Chem. Lett. 44, 259-261 (2015)

23. Maleki, A., Aghaei, M., Ghamari, N.: Facile synthesis of tetrahydrobenzoxanthenones via a one-pot three-component reaction using an eco-friendly and magnetized biopolymer chitosan-based heterogeneous nanocatalyst Appl. Organometal. Chem. 30, 939-942 (2016)

24. Maleki, A., Akhlaghi, E., Paydar, R.: Design, synthesis, characterization and catalytic performance of a new cellulose-based magnetic nanocomposite in the one-pot three-component synthesis of $\alpha$-aminonitriles. Appl. Organometal. Chem. 30, 382-386 (2016)

25. Maleki, A., Kamalzare, M.: Green synthesis of 1,4-benzodiazepines over $\mathrm{La}_{2} \mathrm{O}_{3}$ and $\mathrm{La}(\mathrm{OH})_{3}$ catalysts: possibility of Langmuir-Hinshelwood adsorption. Catal. Commun. 53, 67-71 (2014)

26. Maleki, A., Zand, P., Mohseni, Z.: $\mathrm{Fe}_{3} \mathrm{O}_{4} @ \mathrm{PEG}-\mathrm{SO}_{3} \mathrm{H}$ rod-like morphology along with the spherical nanoparticles: novel green nanocomposite design, preparation, characterization and catalytic application. RSC Adv. 6, 110928-110934 (2016)

27. Maleki, A.: One-pot three-component synthesis of pyrido[2 $\left[2^{\prime}, 1^{\prime}: 2,3\right]$ imidazo[4,5-c]isoquinolines using $\mathrm{Fe}_{3} \mathrm{O}_{4} @ \mathrm{SiO}_{2}-$ $\mathrm{OSO}_{3} \mathrm{H}$ as an efficient heterogeneous nanocatalyst. RSC Adv. 4, 64169-64173 (2014)

28. Maleki, A., Rabbani, M., Shahrokh, Sh: Preparation and characterization of a silica-based magnetic nanocomposite and its application as a recoverable catalyst for the one-pot multicomponent synthesis of quinazolinone derivatives. Appl. Organometal. Chem. 29, 809-814 (2015)

29. Li, H., Zeng, H.Y., Shao, H.W.: Bismuth(III) chloride-catalyzed one-pot Mannich reaction: three-component synthesis of $\beta$-amino carbonyl compounds. Tetrahedron Lett. 50, 6858-6860 (2009)

30. Bigdeli, M.A., Nemati, F., Mahdavinia, G.H.: $\mathrm{HClO}_{4}-\mathrm{SiO}_{2}$ catalyzed stereoselective synthesis of $\beta$-amino ketones via a direct Mannich-type reaction. Tetrahedron Lett. 48, 6801-6804 (2007)
31. Kulkarni, P., Totawar, B., Zubaidha, P.K.: An efficient synthesis of $\beta$-aminoketone compounds through three-component Mannich reaction catalyzed by calcium chloride. Monatsh. Chem. 143, 625-629 (2012)

32. Vadivel, P., Maheswari, C.S., Lalitha, A.: Synthesis of $\beta$-amino carbonyl compounds via Mannich reaction using sulfated MCM41. Int. J. Innov. Tech. Expl. Eng. 2, 267-270 (2013)

33. Wang, X.C., Zhang, L.J., Zhang, Zh, Quan, ZhJ: PEG-OSO ${ }_{3} \mathrm{H}$ as an efficient and recyclable catalyst for the synthesis of $\beta$-amino carbonyl compounds via the Mannich reaction in $\mathrm{PEG}-\mathrm{H}_{2} \mathrm{O}$. Chin. Chem. Lett. 23, 423-426 (2012)

34. Shirini, F., Akbari-Dadamahaleh, S., Mohammad-Khah, A.: Ricehusk-supported $\mathrm{FeCl}_{3}$ nano-particles: introduction of a mild, efficient and reusable catalyst for some of the multi-component reactions. C. R. Chim. 16, 945-955 (2013)

35. Bahrami, K., Khodaei, M.M., Mohammadi, M., Babajani, N.: Ethane-1,2-diaminium hydrogen sulfate: recyclable organocatalyst for one-pot synthesis of $\beta$-amino ketones by a three-component Mannich reaction. J. Chem. Res. 38, 223-225 (2014)

36. Maghsoodlou, M.T., Khorshidi, N., Mousavi, M.R., Hazeri, N., Habibi-Khorassani, S.M.: Starch solution as an efficient and environment-friendly catalyst for one-pot synthesis of $\beta$ aminoketones and 2,3-dihydroquinazolin-4(1H)-ones in EtOH. Res. Chem. Intermed. 41, 7497-7508 (2015)

37. Luo, H.T., Kang, Y.R., Nie, H.Y., Yang, L.M.: Sulfamic acid as a cost-effective and recyclable catalyst for $\beta$-amino carbonyl compounds synthesis. J. Chin. Chem. Soc. 56, 186-195 (2009)

38. Davoodnia, A., Tavakoli-Nishaburi, A., Tavakoli-Hoseini, N.: Carbon-based solid acid catalyzed one-pot Mannich reaction: a facile synthesis of $\beta$-amino carbonyl compounds. Bull. Korean Chem. Soc. 32, 635-638 (2011)

39. Khan, A.T., Parvin, T., Choudhury, L.H.: Bromodimethylsulfonium bromide catalyzed three-component Mannich-type reactions. Eur. J. Org. Chem. 5, 834-839 (2008)

40. Wu, Y., Chen, Ch., Jia, G., Zhu, X., Sun, H., Zhang, G., Zhang, W., Gao, Z.: Salicylato titanocene complexes as cooperative organometallic Lewis acid and Brønsted acid catalysts for threecomponent Mannich reactions. Chem. Eur. J. 20, 8530-8535 (2014)

41. Sharghi, H., Jokar, M.: Highly stereoselective facile synthesis of $\beta$-amino carbonyl compounds via a Mannich-type reaction catalyzed by $\gamma-\mathrm{Al}_{2} \mathrm{O}_{3} / \mathrm{MeSO}_{3} \mathrm{H}$ (alumina/methanesulfonic acid: AMA) as a recyclable, efficient, and versatile heterogeneous catalyst. Can. J. Chem. 88, 14-26 (2010)

42. Mannich, C., Krösche, W.: About a condensation product of formaldehyde, ammonia and antipyrin. Arch. Pharm. 250, 647-667 (1912) 